\title{
Dietary diversity scores: an indicator of micronutrient inadequacy instead of obesity for Chinese children
}

\author{
Wenzhi Zhao ${ }^{1}$, Kai Yu', Shengjie Tan¹, Yingdong Zheng ${ }^{2}$, Ai Zhao ${ }^{3}$, Peiyu Wang ${ }^{3}$ and Yumei Zhang ${ }^{1,4^{*}}$
}

\begin{abstract}
Background: Micronutrient malnutrition affects the well-being of both adults and children. Dietary diversity score (DDS) is a useful evaluation index with a relatively well-developed guideline by FAO. It's meaningful to assess and predict inadequate micronutrient intakes using DDS in Chinese children, after ruling out the risk of obesity coming with more dietary diversity.

Methods: Data for evaluation were extracted from the Nutrition Study of Preschool Children and School Children, which is a cross-sectional study covering 8 cities of China, including 1694 children in kindergartens and primary schools. This study applied DDS to Chinese children to test the validity for micronutrient inadequacy, and then explored the relationship between dietary diversity and obesity.

Results: It reveals that dietary diversity varied with age and place of residence; the older ones and the ones living in rural areas tend to have poorer dietary diversity. Another discovery is that DDS is positively correlated with indicators of micronutrient adequacy, with a score of 6-8 indicating the lowest risk of micronutrient inadequacy in different groups of children. In our study population, dietary diversity is not related with obesity.

Conclusions: Dietary diversity score is a valid indicator to evaluate micronutrient inadequacy in Chinese children, though there is still room for improvement of the method. Besides, the relationship between increase of dietary diversity and risk of obesity should be treated circumspectly.
\end{abstract}

Keywords: Dietary diversity scores, Micronutrient, Nutrient adequacy, Obesity, Chinese children

\section{Background}

Micronutrient malnutrition, which is also called hidden hunger, remains one of the most serious nutritional concerns in both children and adults, and in both developing and developed countries. While overweight and obesity have been a matter of public concern for decades in many countries, ranging from high-income countries to lowand middle-income countries $[1,2]$. China is one of the world's most economically dynamic nations with complex lifestyles, dietary patterns and nutrition transitions. Thus it has a double burden of both undernutrition and

\footnotetext{
* Correspondence: zhangyumei@hsc.pku.edu.cn

${ }^{1}$ Department of Nutrition and Food Hygiene, School of Public Health, Peking University Health Science Center, Xueyuan Road 38, Haidian District, Beijing 100191, China

${ }^{4}$ Beijing Key Laboratory of Toxicological Research and Risk Assessment for Food Safety, Guangqu Road 37, Chaoyang District, Beijing 100022, China Full list of author information is available at the end of the article
}

overnutrition, which is drawing more and more attention $[3,4]$. It is worth noting that both micronutrient malnutrition and obesity have long-term influence on growth development and health of children.

In recent researches, there are several dietary diversity indicators, such as Dietary Diversity Scores (DDS) and Food Variety Score (FVS). DDS is based on food groups, which is more useful than indicators based on an individual food (e.g., FVS) in predicting nutrients adequacy, though the food groups in different researches vary a lot. Besides, attaching certain portion size requirements to DDS will improve the correlation between DDS and micronutrients intake, which has been proved by prior researchers $[5,6]$. Since the simple DDS takes any amount of consumption as positive intake records for a certain category, it may overestimate the intakes of some groups. Research conducted in developing countries 
according to guidelines of FAO [6] or similar operation rules [5] all showed positive relationships between micronutrient adequacy and DDS, such as in non-breast-feeding Filipino children [7] or children in Mali who were under 60 month [8], and even in adults [9].

The inadequacy of iron, zinc, vitamin A and vitamin D is common among Chinese children according to related researches $[10,11]$. In China, a 2002 National Survey reported that the prevalence of vitamin A inadequacy for 3-12 years old children was 9.3\%, and that of Vitamin A marginal inadequacy was about $44.9 \%$ [10]. The prevalence of anemia for boys and girls were respectively 8.7 and $12.5 \%$ in urban areas, and 13.0 and $17.5 \%$ in rural areas, according to a national survey of 7-17 year olds [12]. Micronutrient malnutrition poses a serious threat to health. Every year Vitamin A inadequacy claims the lives of about 670,000 children under 5 and zinc inadequacy claims more than 450,000; and iron-inadequacy anemia results in 136,000 deaths of women and children $[13,14]$. According to the estimation of WHO, Vitamin A supplement programs brought about a $70 \%$ reduction in childhood blindness; zinc programs reduced diarrhea incidence by $27 \%$; folate programs prevented $50 \%$ neural tube birth defects [15].

Most of the micronutrients we need are from daily diet, and therefore it's important to consume a balanced diet containing diverse food. Almost every country's dietary guideline includes items about food diversity, given the fact that a variety of foods may ensure abundant amount of nutrients and other beneficial substances. More and more studies find positive association between dietary diversity and micronutrients adequacy, especially in children from developing countries [5-7, 15]. However, it's possible that diverse diets provide adequate micronutrients with plenty of energy, or even more. Considering the increasing prevalence of obesity in children, circumspect decision should be made to improve their health. There are some researches focusing on relationship between dietary diversity and obesity, though the results vary a lot [16-18]. The latest Chinese Dietary Guidelines published in 2016 stress the importance of food dietary, and make a recommendation of consuming at least 12 food groups per day and 25 food groups per week. There are different ways of dividing food into different food groups, and 10 groups and 17 groups are defined in this paper according to Chinese Food Composition Tables and what children ate.

This study analyzed dietary diversity and micronutrient intakes of Chinese children of 3-12 years old, aiming to validate DDS as an indicator of micronutrient adequacy among children and to quantify an appropriate cut-off point as adequate micronutrient intake. Furthermore, the study analyzed the relationship between childhood obesity and dietary diversity to explore the double burden for Chinese children who were born and grew up in a transition period.

\section{Methods \\ Subjects}

Data were extracted from the Nutrition Study of Preschool Children and School Child, which was conducted from October 2011 to January 2012 in 8 cities of China. Details of the study were described elsewhere $[19,20]$. The analysis included 1694 children in kindergartens and primary schools of 8 cities, aging between 3 and 12 . Informed consents were obtained from their guardians prior to participation. The study was approved by the Ethical Committee of the Health Science Center at Peking University (NO.IRB00001052-11042).

\section{Dietary data}

The food intake data were collected by four questionnaires, each containing a 24-h dietary record table. For every child in kindergartens, one questionnaire was completed by trained investigators to record what the children ate in kindergarten with the help of kindergarteners, and the other questionnaire was fulfilled by the same investigators to record what the children ate at home. For the children in primary school, another two questionnaires were used. All the personnels collecting the data were trained beforehand by professional researchers of the study uniformly.

We used a SAS program which was coded based on Chinese Food Composition Tables (CFCT) 2004 [21] and 2009 [22] (CFCT, National Institute of Nutrition and Food Safety, China CDC), and Standard Tables of Food Composition In Japan (2010) [23] and ingredient lists of common supplements to compute nutrients values, including energy, vitamin $\mathrm{A}$, niacin, vitamin $\mathrm{B} 6$, riboflavin, vitamin $\mathrm{B} 12$, thiamine, vitamin $\mathrm{C}$, folate, calcium, iron and zinc. Related publications and articles were referred to for information about phytate and oxalate in food. If the contents of phytate and oxalate of a certain type of food was missing, a similar food category was suggested.

The content of vitamin A in food was presented as retinol equivalent (RE) with a function of $\mathrm{RE}=\operatorname{vitamin} \mathrm{A}(\mu \mathrm{g})+\beta$-carotene $(\mu \mathrm{g})^{*} 1 / 6+$ other pro-vitamin A carotenoids $(\mu \mathrm{g}) * 1 / 12$ [6]. For calcium, iron and zinc we computed absorbed amount by bioavailability adjustment, according to the absorption percentage of bioavailability. For calcium the absorbed percentages of different food types were determined by the contents of oxalate, $25 \%$ for roots, tubers, grains and legumes; $45 \%$ for fruits and vegetables; $5 \%$ for high oxalate food and $32 \%$ for the rest [6]. With reference to a list of high oxalate food provided by FAO, oxalate values were extracted from research articles to define 
the bioavailability percentage of fruits and vegetables with high oxalate content (high oxalate content meant $>0.45 \mathrm{~g}$ oxalate per $100 \mathrm{~g}$ food). Absorbable iron was assumed to be $6 \%$ for plants and $11 \%$ for animal products. The absorbable zinc was calculated by the ratio of phytate to zinc for each food category (i.e., phytate: zinc molar ratio $=((\mathrm{mg}$ phytate $) 660) /(\mathrm{mg}$ zinc65.4)); if the ratio was over 18 , the percentage of absorption was $30 \%$, otherwise it was $22 \%$ [6].

\section{Dietary diversity scores}

There were three indicators about dietary or food diversity calculated, namely two sets of dietary diversity scores based on 10 food groups (Dietary diversity scores, DDS) and 17 food groups (Seventeen-food-groups dietary diversity score, SDDS), and food variety score (FVS) counting all the food recorded in 24-h dietary records. According to the FAO protocol, DDS was calculated based on 10 food groups, as shown in Table 1 [6]. The child got one point if he or she consumed something at least once from a unique food group in 24-h dietary records, with a threshold of $10 \mathrm{~g}$, which means one had to consume at least $10 \mathrm{~g}$ from a unique food group in the 24-h dietary records to get one point [6]. But for the group of oils and fats, the threshold was set at $2 \mathrm{~g}$ [6]. So the scoring range of DDS is from 1 to 9. To further explore the relationship between childhood obesity and dietary diversity or food variety, we also calculated segmented dietary diversity scores SDDS and FVS. SDDS ranged from 1 to 17 , and its calculation was the same as DDS with a threshold of $10 \mathrm{~g}$. As for FVS, we added up the number of different food items one consumed in 24-h dietary record. All the segmented food groups (showed in Table 1) and single food was defined according to China Food Composition.

\section{Probabilities of adequacy}

We referred to the FAO protocol to calculate probabilities of nutrients adequacy (PA) for a single day, based on distributions of each nutrient which were defined by the mean (i.e., estimated average requirements, EAR) and SD (standard deviation, i.e., the EAR multiplied by the distribution coefficient of variation, CV) [13]. We referred to Chinese Dietary Reference Intakes (DRIs) 2013 edition for EAR (i.e., estimated average requirements), and the $\mathrm{CV}$ was set to $10 \%$ of EAR for all nutrients except vitamin A (20\%), niacin $(15 \%)$ and zinc $(25 \%)[7,24]$. The equation was PA = Probnorm [(estimated Child's intake-EAR)/SD]; the Probnorm function calculated the probability of whether a child's intake was above EAR. For iron, since its distribution wasn't normal, we used the eq. PA = estimated Child's intake/RNI (i.e, recommended nutrient intakes), with RNI extracted from Chinese DRIs. After we got PA of all the 11 micronutrients, we computed the mean probability of adequacy (MPA), applying equal weight to individual nutrients.

\section{Anthropometry data}

Anthropometric information was included in an aforementioned survey. Children were weighed and measured

Table 1 Food groups of 10-food-group dietary diversity scores (DDS) and 17-food-group dietary diversity scores (SDDS)

\begin{tabular}{|c|c|c|c|}
\hline \multicolumn{2}{|l|}{ DDS } & \multicolumn{2}{|l|}{ SDDS } \\
\hline Food group & Note & Food group & Note \\
\hline \multirow[t]{3}{*}{ All starch staples } & \multirow[t]{3}{*}{ With a threshold of $10 \mathrm{~g}$} & Refined grains and cereals & With a threshold of $10 \mathrm{~g}$ \\
\hline & & Other cereals and grains & With a threshold of $10 \mathrm{~g}$ \\
\hline & & Starch tubers and roots & With a threshold of $10 \mathrm{~g}$ \\
\hline \multirow[t]{3}{*}{ Vitamin A-rich vegetables \& fruit } & \multirow[t]{3}{*}{ With a threshold of $10 \mathrm{~g}$} & Vitamin A-rich dark-green leafy vegetables & With a threshold of $10 \mathrm{~g}$ \\
\hline & & Vitamin A-rich deep yellow/orange/red vegetables & With a threshold of $10 \mathrm{~g}$ \\
\hline & & Vitamin A-rich fruits & With a threshold of $10 \mathrm{~g}$ \\
\hline All other fruits & With a threshold of $10 \mathrm{~g}$ & Vitamin C-rich vegetables & With a threshold of $10 \mathrm{~g}$ \\
\hline \multirow[t]{2}{*}{ All other vegetables } & \multirow[t]{2}{*}{ With a threshold of $10 \mathrm{~g}$} & Vitamin C-rich fruits & With a threshold of $10 \mathrm{~g}$ \\
\hline & & All other fruits \& vegetables & With a threshold of $10 \mathrm{~g}$ \\
\hline All legumes \& nuts & With a threshold of $10 \mathrm{~g}$ & All legumes \& nuts & With a threshold of $10 \mathrm{~g}$ \\
\hline Oil and fat & With a threshold of $2 \mathrm{~g}$ & Oil and fat & With a threshold of $2 \mathrm{~g}$ \\
\hline \multirow[t]{2}{*}{ Meat, poultry, fish } & \multirow[t]{2}{*}{ With a threshold of $10 \mathrm{~g}$} & Meat, poultry, fish & With a threshold of $10 \mathrm{~g}$ \\
\hline & & Organ meat & With a threshold of $10 \mathrm{~g}$ \\
\hline All dairy & With a threshold of $10 \mathrm{~g}$ & All dairy & With a threshold of $10 \mathrm{~g}$ \\
\hline Eggs & With a threshold of $10 \mathrm{~g}$ & Eggs & With a threshold of $10 \mathrm{~g}$ \\
\hline \multirow[t]{2}{*}{ Other food } & \multirow[t]{2}{*}{ Exclude calculation } & $\begin{array}{l}\text { Desserts, candy, sugar-sweetened beverages } \\
\text { and Puffing Food }\end{array}$ & With a threshold of $10 \mathrm{~g}$ \\
\hline & & Other food & With a threshold of $10 \mathrm{~g}$ \\
\hline
\end{tabular}


without heavy clothing or shoes by trained investigators according to Chinese specification for children physical examination service, to the nearest $0.1 \mathrm{~cm}$ or $0.1 \mathrm{~kg}$. For weight and height, calibrated scale (Suhong YES-S, RGZ-120; Jiangsu, China) was used. First, BMI was calculated for every child by dividing body weight (in kilograms) by height (in meters squared). LiHui's study based on Chinese children was referred to to diagnose overweight and obesity by BMI [25]. Then related Zscores were computed by WHO Anthro and WHO Anthroplus, including HAZ (Height for age Z-score), WAZ (Weight for age Z-score), WHZ (Weight for height Z-score) and BAZ (BMI for age Z-score).

\section{Statistical analysis}

The analysis was conducted with SPSS version 15.0. $P<0.05$ was considered significant for all analysis. Descriptive analysis applied to continuous variables was showed as mean and SD, while categorical data were presented as frequency and percentage. Percentage of children who consumed different food groups according to DDS was sorted. Pearson's correlation was tested by age group and residence between PA/MPA and DDS, with energy intake as a covariate. Sensitivity/ specificity analysis was performed to determine the DDS cut-off value for micronutrients inadequacy, using MPA as the gold standard. A certain MPA threshold was used to categorize children into low and high micronutrient intakes groups. Two MPA cut-off values of 0.50 and 0.75 were applied. Spearman's correlation was tested between DDS, SDDS, FVS and BMI, Z-scores.

\section{Result}

1694 children from kindergartens and primary schools were analyzed in this study, including 878 boys and 816 girls, and about $75 \%$ of them were from urban areas. The number of children who were $\leq 6$ years was 983 , and that of children who were $>6$ years was 711 . The sociodemographic characteristics of investigated children were showed in Table 2.

The analysis of DDS, micronutrient intakes and PA/ MPA of investigated children by age groups and residences was listed in Table 3. Age groups were determined by the fact of Chinese school age, and most of the investigated children between 6 to 7 years old were in kindergartens. The DDS distribution was significantly different between younger and older children, urban and rural children. Older children and children living in rural areas were more likely to get a lower score, and it's significant that younger children ( $\leq 6$ years) consumed more food groups than older children ( $>6$ years), which meant that children in urban areas had better dietary diversity than those in rural areas. The micronutrients intakes and PA/MPA of investigated children shared the same trend, that was children of younger age group or living in rural areas were in better condition, for most micronutrients. It should be noticed that the intakes of minerals such as calcium, iron and zinc decreased by 70 $90 \%$ after bioavailability adjusting, which had a big influence on the MPA. The MPA was 0.42 for children under 6, while 0.26 for children over 6. The significant difference was initially explained by the PAs of kinds of vitamin, while the PAs of minerals were both low in two groups.

As shown in Fig. 1, the probability of every food group being consumed was different and changed with the increase of DDS, and for children who got a DDS of 1 , they just ate all starch staples by $100 \%$ that day. The difference between age groups and places of residence was

Table 2 Demographic characteristics of investigated children

\begin{tabular}{|c|c|c|c|}
\hline Characteristics & Note & Number, Percentage & \\
\hline \multirow[t]{2}{*}{ Nationality } & Han nationality & $1678,96.9 \%$ & \\
\hline & Minority nationality & $54,3.1 \%$ & \\
\hline \multirow[t]{5}{*}{ Per capita monthly income } & $\leq 1500 \mathrm{RMB}$ & $465,27.7 \%$ & \\
\hline & $1501 \sim 3000$ RMB & $523,31.1 \%$ & \\
\hline & $3001 \sim 6000$ RMB & $349,20.8 \%$ & \\
\hline & $>6000 \mathrm{RMB}$ & $342,20.4 \%$ & \\
\hline & & The mother of children & The Father of children \\
\hline \multirow[t]{3}{*}{ Educational level } & Primary school or below & $175,10.1 \%$ & $86,5.0 \%$ \\
\hline & Secondary education & $1294,74.8 \%$ & $1289,75.6 \%$ \\
\hline & Bachelor degree or above & $260,15.0 \%$ & $329,19.3 \%$ \\
\hline \multirow[t]{4}{*}{ Occupation } & Unemployed & $608,36.0 \%$ & $129,7.6 \%$ \\
\hline & Office work & $467,27.6 \%$ & $680,40.2 \%$ \\
\hline & Manual work & $432,25.6 \%$ & $549,32.5 \%$ \\
\hline & Other work & $183,10.8 \%$ & $332,19.6 \%$ \\
\hline
\end{tabular}


Table 3 Distribution of DDS, nutrients intake and PA/MPA by age groups and residences

\begin{tabular}{|c|c|c|c|c|c|c|}
\hline \multirow[t]{2}{*}{ Items } & \multirow[t]{2}{*}{ Note } & \multirow[t]{2}{*}{ Total } & \multicolumn{2}{|l|}{ Age group } & \multicolumn{2}{|l|}{ Residence } \\
\hline & & & $\leq 6$ years & $>6$ years & Urban & Rural \\
\hline$\overline{\mathrm{DDS}}$ & DDS & $6.3 \pm 1.5$ & $6.8 \pm 1.3^{* * *}$ & $5.6 \pm 1.5^{* * *}$ & $6.4 \pm 1.6^{* * *}$ & $5.8 \pm 1.3^{* * *}$ \\
\hline \multirow[t]{15}{*}{ Nutrients Intake } & Energy(Kcal) & $1432.7 \pm 572.1$ & $1448.7 \pm 560.6$ & $1410.6 \pm 587.2$ & $1438.4 \pm 544.6$ & $1415 \pm 650.1$ \\
\hline & Vitamin B1(mg) & $0.7 \pm 0.4$ & $0.7 \pm 0.4^{* * *}$ & $0.6 \pm 0.3^{* * *}$ & $0.7 \pm 0.4^{* * *}$ & $0.6 \pm 0.3^{* * *}$ \\
\hline & Vitamin B2(mg) & $0.8 \pm 0.4$ & $0.8 \pm 0.4^{* *}$ & $0.7 \pm 0.4^{* *}$ & $0.7 \pm 0.4^{* *}$ & $0.8 \pm 0.5^{* *}$ \\
\hline & Niacin(mg) & $10.2 \pm 5.7$ & $10.2 \pm 5.5$ & $10.1 \pm 6.1$ & $10.9 \pm 5.8^{* * *}$ & $7.9 \pm 4.9^{* * *}$ \\
\hline & Vitamin B6(mg) & $0.6 \pm 0.3$ & $0.6 \pm 0.3^{* * *}$ & $0.5 \pm 0.3^{* *}$ & $0.6 \pm 0.3^{* * *}$ & $0.4 \pm 0.3^{* * *}$ \\
\hline & Folate $(\mu \mathrm{g})$ & $149.0 \pm 98.5$ & $152.9 \pm 86.6$ & $143.7 \pm 112.8$ & $142.7 \pm 89.3^{* * *}$ & $168.5 \pm 120.7^{* * *}$ \\
\hline & Vitamin B12( $\mu \mathrm{g})$ & $2.4 \pm 3.8$ & $2.4 \pm 3.4$ & $2.3 \pm 4.2$ & $2.7 \pm 4.2^{* * *}$ & $1.4 \pm 1.7^{* * *}$ \\
\hline & Vitamin C(mg) & $58.1 \pm 46.2$ & $59.3 \pm 41.7$ & $56.5 \pm 51.8$ & $58.5 \pm 45.7$ & $56.9 \pm 47.7$ \\
\hline & Vitamin A( $\mu g$ RE) & $259.8 \pm 221.9$ & $285.0 \pm 211.9^{* * *}$ & $224.9 \pm 230.6^{* * *}$ & $280.3 \pm 236.5^{* * *}$ & $196.3 \pm 152.3^{* * *}$ \\
\hline & Absorbed Calcium(mg) & $109.3 \pm 74.8$ & $112.7 \pm 80^{*}$ & $104.4 \pm 66.6^{*}$ & $115.4 \pm 75.4^{* * *}$ & $90.2 \pm 69.6^{* * *}$ \\
\hline & Absorbed Iron(mg) & $1.0 \pm 0.6$ & $1.0 \pm 0.5$ & $1.0 \pm 0.7$ & $1.0 \pm 0.6$ & $1.0 \pm 0.5$ \\
\hline & Absorbed Zinc(mg) & $2.1 \pm 1.0$ & $2.1 \pm 0.9$ & $2.1 \pm 1.1$ & $2.2 \pm 1.0^{* * *}$ & $1.9 \pm 0.9^{* * *}$ \\
\hline & Calcium(mg) & $341.5 \pm 228.5$ & $353.1 \pm 245.9^{*}$ & $325.4 \pm 201.1^{*}$ & $356.5 \pm 228.7^{* * *}$ & $294.9 \pm 221.6^{* * *}$ \\
\hline & Iron(mg) & $14.4 \pm 8.1$ & $14.4 \pm 6.9$ & $14.4 \pm 9.6$ & $14.2 \pm 7.9$ & $15.0 \pm 8.9$ \\
\hline & Zinc(mg) & $7.4 \pm 3.5$ & $7.5 \pm 3.3$ & $7.3 \pm 3.6$ & $7.7 \pm 3.5^{* * *}$ & $6.7 \pm 3.3^{* * *}$ \\
\hline \multirow[t]{12}{*}{ PA/MPA } & PA(Vitamin B1) & $0.39 \pm 0.45$ & $0.55 \pm 0.46^{* * *}$ & $0.17 \pm 0.33^{* * *}$ & $0.42 \pm 0.46^{* * *}$ & $0.28 \pm 0.39^{* * *}$ \\
\hline & PA(Vitamin B2) & $0.50 \pm 0.46$ & $0.64 \pm 0.43^{* * *}$ & $0.31 \pm 0.42^{* * *}$ & $0.52 \pm 0.45$ & $0.45 \pm 0.46$ \\
\hline & PA(Niacin) & $0.66 \pm 0.42$ & $0.76 \pm 0.37^{* * *}$ & $0.51 \pm 0.45^{* * *}$ & $0.73 \pm 0.40^{* * *}$ & $0.44 \pm 0.42^{* * *}$ \\
\hline & PA(Vitamin B6) & $0.31 \pm 0.42$ & $0.43 \pm 0.45^{* * *}$ & $0.14 \pm 0.31^{* * *}$ & $0.35 \pm 0.44^{* * *}$ & $0.17 \pm 0.33^{* * *}$ \\
\hline & PA(Folic Acid) & $0.32 \pm 0.42$ & $0.44 \pm 0.44^{* * *}$ & $0.15 \pm 0.33^{* * *}$ & $0.31 \pm 0.42$ & $0.34 \pm 0.44$ \\
\hline & PA(Vitamin B12) & $0.65 \pm 0.46$ & $0.76 \pm 0.41^{* * *}$ & $0.50 \pm 0.47^{* * *}$ & $0.72 \pm 0.43^{* * *}$ & $0.44 \pm 0.48^{* * *}$ \\
\hline & PA(Vitamin C) & $0.53 \pm 0.47$ & $0.64 \pm 0.46^{* * *}$ & $0.36 \pm 0.45^{* * *}$ & $0.53 \pm 0.48$ & $0.50 \pm 0.47$ \\
\hline & PA(Vitamin A) & $0.33 \pm 0.41$ & $0.47 \pm 0.42^{* * *}$ & $0.15 \pm 0.30^{* * *}$ & $0.38 \pm 0.42^{* * *}$ & $0.19 \pm 0.33^{* * *}$ \\
\hline & PA(Calcium) & $0 \pm 0.03$ & $0 \pm 0.04^{*}$ & $0 \pm 0^{*}$ & $0 \pm 0.02$ & $0 \pm 0.05$ \\
\hline & PA(Iron) & $0.64 \pm 0.26$ & $0.66 \pm 0.25^{* *}$ & $0.61 \pm 0.27^{* *}$ & $0.65 \pm 0.26^{* *}$ & $0.60 \pm 0.28^{* *}$ \\
\hline & PA(Zinc) & $0.05 \pm 0.14$ & $0.08 \pm 0.17^{* * *}$ & $0.02 \pm 0.07^{* * *}$ & $0.06 \pm 0.15^{* * *}$ & $0.02 \pm 0.06^{* * *}$ \\
\hline & MPA & $0.39 \pm 0.26$ & $0.49 \pm 0.26^{* * *}$ & $0.26 \pm 0.19^{* * *}$ & $0.42 \pm 0.27^{* * *}$ & $0.31 \pm 0.22^{* * *}$ \\
\hline
\end{tabular}

$P A$ probabilities of nutrients adequacy, MPA mean probability of adequacy; ${ }^{*}, P<0.05 ;{ }^{* *}, P<0.01 ; * * *, P<0.001$

significant. Groups such as all starch staples, oils and fats, other vegetables, meat, poultry, fish were the most frequently consumed food.

The change of PA/MPA by DDS was shown in Fig. 2. For all vitamins, the PA tended to increase with higher score in DDS, and PA of vitamin B12 and C were almost linearly associated with DDS. For minerals, however, the trends were different, and the lines showing PA of minerals changing with DDS were flat and gentle. We further analyzed the correlations between PA/MPA and DDS, and found that only the correlation between PA of absorbed zinc and DDS was non-significant. The correlation coefficient between MPA and DDS was 0.372 . When stratifying investigated children by age $(\leq 6$ years and $>6$ years), the correlations coefficient between MPA and DDS were 0.148 and 0.338 , respectively. While when the investigated children were stratified by place of residence (Urban and Rural area), the correlation coefficient between MPA and DDS were 0.349 and 0.296. Though the FAO protocol was designed to assess children under 6 , there was no advantage in our "matched" population.

Figure 3 showed sensitivity and specificity of DDS as an indicator to predict or evaluate micronutrient intake adequacy of investigated children, with MPA as the golden standard. Sensitivity indicated low DDS correctly reflected the percentage of investigated children truly at risk of micronutrients inadequacy (low MPA). Specificity showed the percentage of investigated children with no risk of micronutrient inadequacy (high MPA) who were defined with higher DDS properly. We defined the intersection of sensitivity and specificity lines as the DDS cut-off value to classify the two groups of micronutrients 

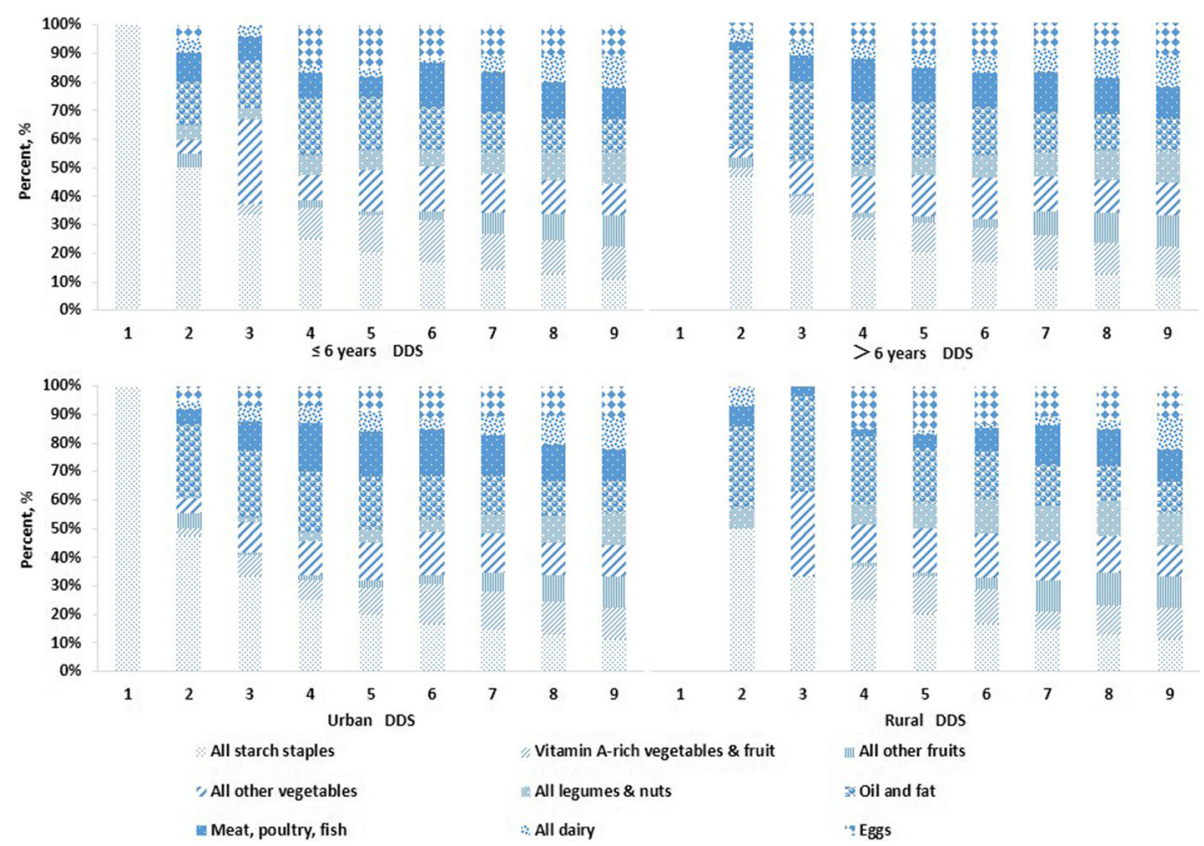

Fig. 1 Probability of investigated children consuming food groups by DDS, divided by age groups and residences

inadequacy and adequacy. It's reasonable that intersection of larger MPA corresponded to higher DDS. Though the two groups of lines nearly overlapped in urban children $\leq 6$ years, and the intersection of larger MPA corresponded to lower DDS in rural children $\leq 6$ years. Comparing the DDS cut-offs in different ageresidence groups, almost all the intersections of $\mathrm{MPA}=0.75$ were around 7 or 8 , except for that of rural. So if one investigated child in urban areas got 7 or 8 in DDS system, we may worry less about him for risk of micronutrient inadequacy. But for children in rural areas, we should lower the DDS to 6 to determine they were in danger of micronutrient inadequacy or not.

Then we conducted correlation analysis of food diversity and anthropometric data, especially on indicators about overweight and obesity. The descriptive analysis was shown in Table 4. Just as DDS, there was significant difference between 2 age groups and places of residence in SDDS and FVS, and the trend was that children of younger age group and urban areas consumed more food items or groups. For growth indicators and obesity rate, there was only significant difference between two

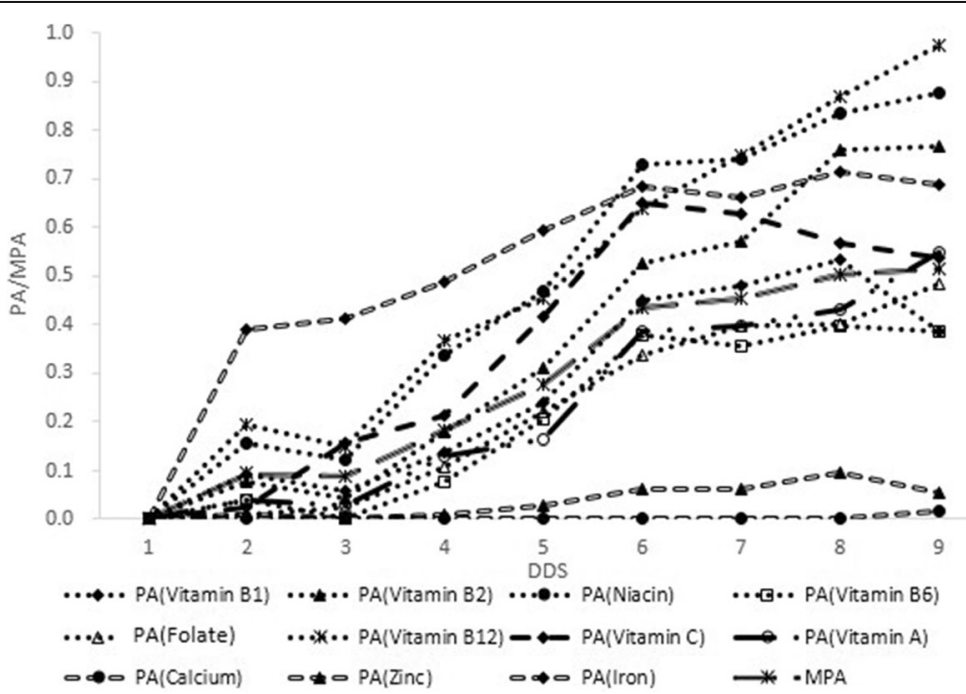

Fig. 2 PA of micronutrients and MPA at different levels of DDS from investigated children 


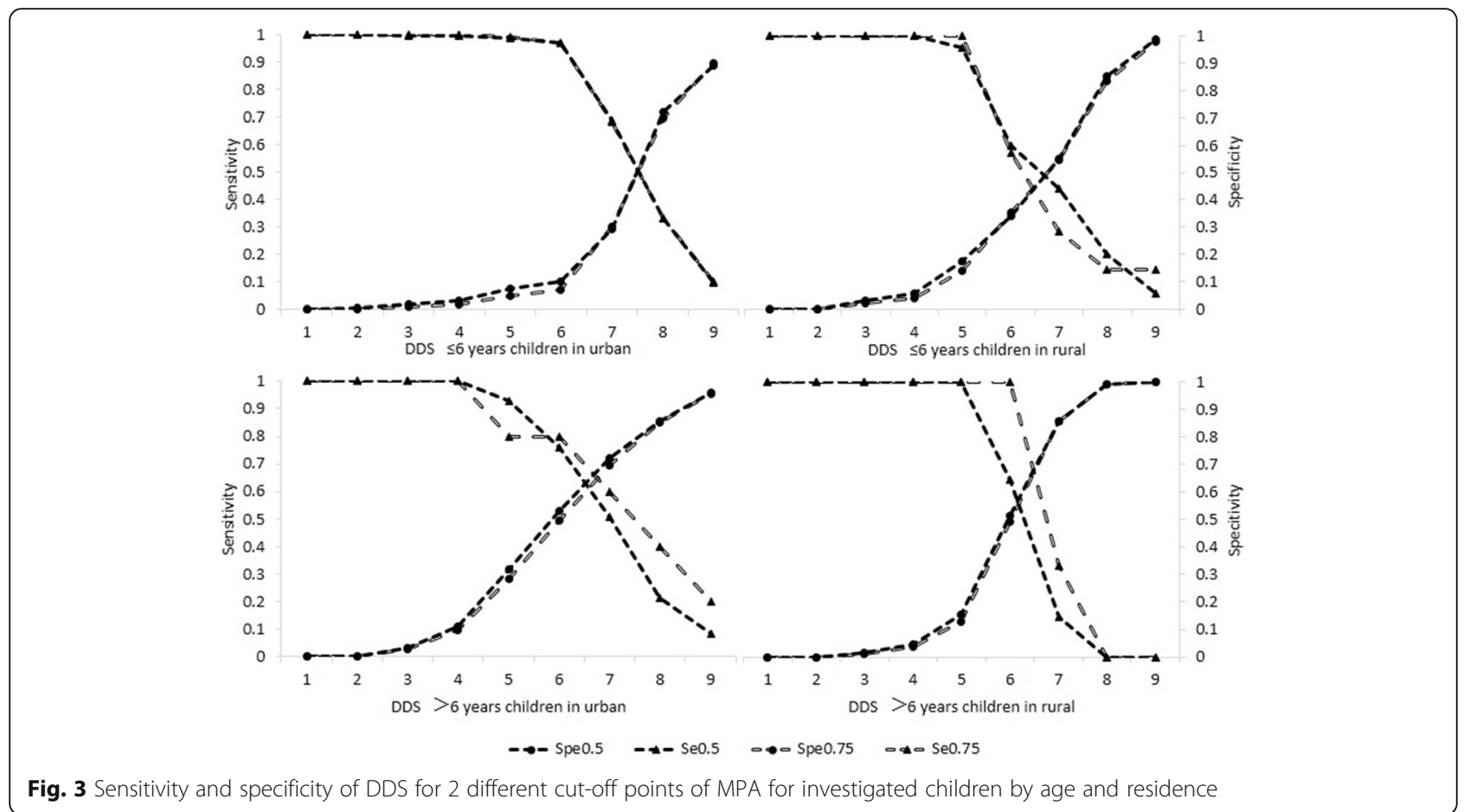

age groups in BMI, but when comparing children from urban areas and rural areas, their means of BMI, WHZ, WAZ, BAZ and obesity rate were all significantly different. The correlation analysis of dietary diversity indicators and growth indicators were shown in Table 5. It's interesting that in children $>6$ years old, dietary diversity indicators were negatively correlated with BMI and BAZ, which was just opposite to those of children $\leq 6$ years old.

Furthermore, we compared 3 food diversity indicators between children who had obesity problem (overweight or obesity) and that who did not. The results were shown in Fig. 4. In total, we failed to find significant relationship between food diversity indicators and obesity status, too. But in different age groups and residence groups, there were significant differences. When children who were overweight or obesity were defined as obese children, obesity children in the younger children group got higher SDDS and FVS, while obesity children in the older children group got lower DDS, SDDS and FVS. When only children who were obesity were defined as obesity children, the results were similar: obesity children in urban areas got lower DDS than non-obesity children.

\section{Discussion}

Lack of dietary diversity is common among underserved population from developing countries, for the reason

Table 4 Distribution of SDDS, FVS, Z-scores and rate of overweight/obesity by age groups and residences

\begin{tabular}{|c|c|c|c|c|c|c|}
\hline \multirow[t]{2}{*}{ Item } & \multirow[t]{2}{*}{ Note } & \multirow[t]{2}{*}{ Total } & \multicolumn{2}{|l|}{ Age group } & \multicolumn{2}{|l|}{ Residence } \\
\hline & & & $\leq 6$ years & $>6$ years & Urban & Rural \\
\hline \multirow[t]{2}{*}{ Food diversity } & SDDS & $7.5 \pm 2.1$ & $8.4 \pm 1.7^{* * *}$ & $6.2 \pm 1.8^{* * *}$ & $7.7 \pm 2.2^{* * *}$ & $6.9 \pm 1.6^{* * *}$ \\
\hline & FVS & $13.2 \pm 5.3$ & $15.7 \pm 4.7^{* * *}$ & $9.6 \pm 3.7^{* * *}$ & $14.1 \pm 5.5^{* * *}$ & $10.3 \pm 2.8^{* * *}$ \\
\hline \multirow[t]{5}{*}{ Growth indicator } & $\mathrm{BMl}$ & $16.6 \pm 8.1$ & $15.8 \pm 3.0^{* * *}$ & $17.3 \pm 10.9^{* * *}$ & $17.0 \pm 9.2^{* * *}$ & $15.2 \pm 2.5^{* * *}$ \\
\hline & WHZ & $0.2 \pm 1.5$ & $0.2 \pm 1.5$ & & $0.3 \pm 1.5^{* *}$ & $-0.2 \pm 1.1^{* *}$ \\
\hline & WAZ & $0.3 \pm 1.3$ & $0.3 \pm 1.2$ & $0.3 \pm 1.3$ & $0.4 \pm 1.3^{* * *}$ & $-0.1 \pm 1.1^{* * *}$ \\
\hline & $\mathrm{HAZ}$ & $0.3 \pm 1.2$ & $0.3 \pm 1.2$ & $0.2 \pm 1.2$ & $0.3 \pm 1.2$ & $0.3 \pm 1.2$ \\
\hline & $\mathrm{BAZ}$ & $0.1 \pm 1.6$ & $0.2 \pm 1.6^{*}$ & $0.1 \pm 1.4^{*}$ & $0.4 \pm 1.5^{* * *}$ & $-0.6 \pm 1.4^{* * *}$ \\
\hline \multirow[t]{2}{*}{ Obesity rate } & Overweight and obesity & $375,22.1 \%$ & $197,20.0 \%$ & $178,25.0 \%$ & $344,26.9 \%^{* * *}$ & $31,7.5 \%^{* * *}$ \\
\hline & Obesity & $154,9.1 \%$ & $86,8.7 \%$ & $68,9.6 \%$ & $142,11.1 \% \%^{* * *}$ & $12,2.9 \% * * *$ \\
\hline
\end{tabular}

SDDS Seventeen-food-groups dietary diversity score, FVS food variety score, HAZ Height for age Z-score, WAZ Weight for age Z-score, WHZ Weight for height Zscore, BAZ BMI for age Z-score; --, not applicable; *, $P<0.05 ;{ }^{* *}, P<0.01 ; * * *, P<0.001$ 
Table 5 Correlation analysis of dietary diversity indicators and growth indicators

\begin{tabular}{|c|c|c|c|c|c|c|c|c|c|}
\hline \multirow[t]{2}{*}{ Variable } & \multicolumn{3}{|l|}{ DDS } & \multicolumn{3}{|l|}{ SDDS } & \multicolumn{3}{|l|}{ FVS } \\
\hline & Total & $\leq 6$ years & $>6$ years & Total & $\leq 6$ years & $>6$ years & Total & $\leq 6$ years & $>6$ years \\
\hline $\mathrm{BMI}$ & $-0.109^{* *}$ & 0.048 & $-0.085^{*}$ & $-0.113^{* *}$ & $0.158^{* *}$ & -0.124 & $-0.111^{* *}$ & $0.186^{* *}$ & $-0.135^{* *}$ \\
\hline $\mathrm{WHZ}$ & -0.037 & -0.037 & - & $0.118^{* *}$ & $0.118^{* *}$ & - & $0.164^{* *}$ & $0.164^{* *}$ & - \\
\hline WAZ & 0.042 & 0.037 & 0.030 & $0.084^{* *}$ & $0.151^{* *}$ & -0.042 & $0.082^{* *}$ & $0.137^{* *}$ & -0.037 \\
\hline $\mathrm{HAZ}$ & $0.067^{* *}$ & 0.012 & $0.078^{*}$ & $0.060^{*}$ & $0.066^{*}$ & 0.002 & $0.048^{*}$ & 0.015 & 0.017 \\
\hline BAZ & 0 & 0.051 & $-0.076^{*}$ & 0.036 & $0.166^{* *}$ & $-0.120^{*}$ & $0.048^{*}$ & $0.193^{* *}$ & $-0.130^{* *}$ \\
\hline
\end{tabular}

DDS dietary diversity score of 9 food groups, SDDS Seventeen-food-groups dietary diversity score, FVS food variety score, HAZ Height for age Z-score, WAZ Weight for age Z-score, WHZ Weight for height Z-score, BAZ BMI for age Z-score; --, not applicable; ${ }^{*}, P<0.05 ;{ }^{* *}, P<0.01$

that their diets are largely based on starchy staples, with little or no animal products and few fresh fruits and vegetables. The plant-based diets will result in inadequate mineral micronutrients intake or poor absorption. In our study, the investigated children consume 6 food groups on average, and the older children consume fewer groups than the younger ones. The most frequently consumed food groups are starch staples, oils and fats, other vegetables, meat, poultry, fish, and dairy, while the groups of legumes, pulses and nuts, dairy and other fruits are less likely to be consumed. Compared with studies conducted in other developing countries such as Kenya, the Philippines, Mali and South Africa $[7-9,26]$, the studied sample consumed more food groups.

In our study the older children tend to get a lower DDS score, which is contrary to common sense that older children should have more chance and better appetite to eat different kinds of food. In China, people pay more attention on children, normally it has been suggested that there should be one dietician at least in the kindergarten who is responsible for the children's diets. There are several kinds of weekly dietary plan made according to Chinese dietary guidelines for different age of children in kindergartens which are administrated by Health Bureau. And the diets for kindergarten children are thought highly of and pleased by children and their parents. However, in primary school, things are more different, and there are only a few of schools making their dietary plan for students. The primary school children also eat lunch at school, while their dietary habits differ a lot, and related studies show that a lot of students do not like lunches supplied in school and food waste is common in students $[27,28]$. The shift of the guardians' focus from children's growth to their study, and the formation of independent selectivity may be responsible for the trend. Children in rural areas have worse dietary diversity than those in urban areas, which may be explained by household socioeconomic factors $[5,18]$.

For children, micronutrients do play an important role in their growth and development. In DDS system, PA acts as an indicator of intake adequacy, while the limit is being defined subjectively according to researchers [5]. There are positive correlations between PA of most micronutrients and DDS, meaning the more food groups one consumed, the lower risk of him being exposed to micronutrient inadequacy. The Pearson's correlation between DDS and MPA is statistically significant, as has been backed by similar researches, such as those in Philippines (0.44), Mali (0.39) and Kenya (0.32) [7-9]. For vitamins, especially vitamin B12 and vitamin C, consuming more food groups will ensure adequate intake. However, for zinc and calcium, consuming more food

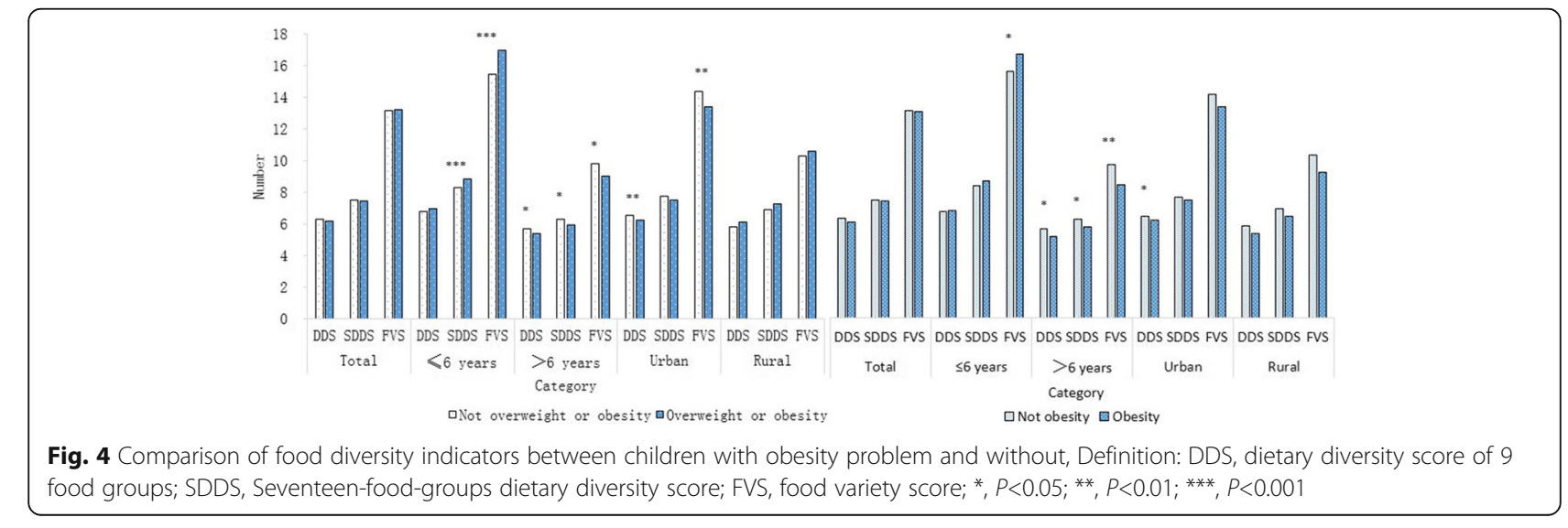


groups seldom affects the absorbed dose, suggesting that we should pay attention to lower bioavailability of minerals. The fact that after bioavailability adjustment, the content of mineral micronutrients decreases a lot, suggests that diet mostly based on plants is barely enough to provide balanced nutrients $[29,30]$. There are few studies or official documents focusing on content of "disturbed substances" in food materials and their influence on nutriment intakes in China and the disturbed substances involve all the chemical substances that will obstruct the absorption of minerals in alimentary canal, such as phytate, oxalate and polyphenols in plants. It is time we take the natural disturbance seriously and draw on related studies in making our guidelines about dietary or nutrition.

There are two most important steps we did to calculate PA of minerals, supplementing the content of "disturbed substances" in plant food for bioavailability adjustment and referring to the Chinese DRIs. As mentioned earlier, we refer to a lot of studies to get the content of phytate and oxalate in different food. However, the content of phytate and oxalate is greatly affected by planting environment and processing method in plant $[31,32]$. When calculated with Chinese DRIs, the PA is inevitable to deviate from the reality of Chinese children. Though the trend of PA is similar to that of DDS, that is PA and MPA of younger children and children in urban areas are higher. So the combination of DDS and PA/ MPA shows that in our study population children in kindergarten and children in urban areas are in better micronutrient condition.

In validation tests of DDS and adequate micronutrient intake, the point of intersection of sensitivity and specificity lines indicates the distinguishable score, separating children with high risk of micronutrient inadequacy from the ones with low risk. As a next step, we could just use DDS cut-off to screen children at high risk. Our research provides different cut-offs according to children's age and place of residence. For younger children in urban areas, one has to consume nearly 8 food groups to avoid risk of micronutrient inadequacy; while younger children in rural areas and all the older children should consume 6 or 7 food groups to be free from the risk. It's reasonable that in the population with less dietary diversity, we should lower the threshold of DDS distinguishing higher risk of micronutrient inadequacy.

In our study population, we failed to find the relationship between DDS and overweight or obesity, nor that between SDDS and overweight or obesity, nor that between FVS and overweight or obesity, similar to previous studies $[16,17]$. Though in other researches, they do find relationship between dietary diversity and obesity $[33,34]$. The positive results in subgroup analysis are in accordance with the two opinions in part. In children of higher socio-economic status or living in urban areas, obesity children tend to have low dietary diversity [16]. However, the opposite trend of DDS, SDDS and FVS changing with obesity status in the two age groups called for more in-depth researches. The dilemma is that, in younger children the increase of dietary diversity improves micronutrient status without bringing in risk of obesity, and the older children face a more complex situation-higher dietary diversity coming with better micronutrient status but higher risk of obesity, according to the preliminary results. There is a lot of work to do to explain and solve the problem.

One of the limitations of our study is that we collected dietary information just for $24 \mathrm{~h}$, and it is just representative for daily life in kindergartens or schools, which will affect the validity of PA/MPA and DDS. We should prolong the data collection period in future research, such as a 3-day dietary recall including workdays and off days. Furthermore, we need to update our food composition table based on Chinese food, adding the contents of some important nutrients and substances disturbing absorption. Guidelines or standards from other countries cannot meet all the needs because the dietary is so different. Another shortage is that the guidelines of FAO are applicable for non-breastfeeding children aged between 2 and 6 years old, but we expand the recommended population, which may affect the validity of the sensitivity and specificity estimate for older children.

Our study is the first one to evaluate Chinese children's dietary diversity with the FAO guidelines. We found positive correlation between DDS and MPA/PA, but failed to find that of DDS/SDDS/FVS and obesity status. The results of different subgroups varied greatly, and we should evaluate the nutrition status of different populations separately. The thresholds of DDS provided reference for future screening projects [11]. Currently, there is no quick and easy way to determine the micronutrient adequacy of the diet of children in China, and detection of children's blood trace elements is an expensive but not necessary test for some nutrients such as calcium, although it is formal in some hospitals. The health status of children under school age are managed by community health service centers and each child has several times of health examination according to principles of the Health Bureau. So the development and promotion of DDS as a screening tool in hospitals and health service centers is helpful for doctors to assess nutritional status of children.

\section{Conclusions}

Dietary diversity score is a valid indicator to evaluate micronutrient inadequacy in Chinese children, though there is still room for improvement of the method. Besides, the relationship between increase of dietary 
diversity and risk of obesity should be treated circumspectly in Chinese children.

\section{Abbreviations}

BAZ: BMI for age Z-score; BMI: Body mass index; CFCT: Chinese food composition Tables; CV: Coefficient of variation; DDS: Dietary diversity score; DRIs: Dietary reference intake; EAR: Estimated average requirements; FVS: Food variety score; HAZ: Height for age Z-score; MPA: Mean probability of adequacy; PA: Probabilities of nutrients adequacy; RE: Retinol equivalent; RNI: Recommended nutrient intakes; SD: Standard deviation;

SDDS: Seventeen-food-groups dietary diversity score; WAZ: Weight for age Z-score; WHZ: Weight for height Z-score

\section{Acknowledgments}

The authors wish to thank personnel devoted to the field investigations of every city for their efforts.

\section{Funding}

There was no special funding for the research.

\section{Availability of data and materials}

The dataset of the study is available from the corresponding author upon reasonable request.

\section{Authors' contributions}

Research conception and design was provided by PW \& YZ1. Research was performed by WZ, KY, ST, AZ \& YZZ. Data was analyzed and results were interpreted by WZ, KY, ST, YZ2 \& YZ1. Manuscript was prepared by WZ, KY, $S T, A Z \& Y Z 2$. Manuscript was critically revised by PW \& YZ1. Final manuscript was approved by WZ, KY, ST, AZ, YZ2, PW \& YZ1. All authors read and approved the final manuscript. Note: YZ1 meant Yumei Zhang; YZ2 meant Yingdong Zheng.

\section{Competing interests}

The authors declare that they have no competing interests.

\section{Consent for publication}

Not applicable.

\section{Ethics approval and consent to participate}

This study was approved by the Ethical Committee of the Health Science Center at Peking University (NO.IRB00001052-11042). If the children and their guardians agreed to take part in the survey after being fully informed of the research, written informed consents were obtained from their legal guardians prior to participation.

\section{Publisher's Note}

Springer Nature remains neutral with regard to jurisdictional claims in published maps and institutional affiliations.

\begin{abstract}
Author details
${ }^{1}$ Department of Nutrition and Food Hygiene, School of Public Health, Peking University Health Science Center, Xueyuan Road 38, Haidian District, Beijing 100191, China. ${ }^{2}$ Department of Epidemiology and Biostatistics, School of Public Health, Peking University Health Science Center, Xueyuan Road 38, Haidian District, Beijing 100191, China. ${ }^{3}$ Department of Social Medicine and Health Education, School of Public Health, Peking University Health Science Center, Xueyuan Road 38, Haidian District, Beijing 100191, China. ${ }^{4}$ Beijing Key Laboratory of Toxicological Research and Risk Assessment for Food Safety, Guangqu Road 37, Chaoyang District, Beijing 100022, China.
\end{abstract}

Received: 7 December 2016 Accepted: 7 May 2017

Published online: 12 May 2017

\section{References}

1. Tzioumis E, Adair LS. Childhood dual burden of under- and overnutrition in low- and middle-income countries: a critical review. Food Nutr Bull. 2014;35(2):230-43.
2. Kroker-Lobos MF, Pedroza-Tobias A, Pedraza LS, Rivera JA. The double burden of undernutrition and excess body weight in Mexico. Am J Clin Nutr. 2014;100(6):1652S-8S.

3. Piernas C, Wang D, Du S, Zhang B, Wang Z, Su C, et al. The double burden of under- and overnutrition and nutrient adequacy among Chinese preschool and school-aged children in 2009-2011. Eur J Clin Nutr. 2015; 69(12):1323-9.

4. Haddad L, Cameron L, Barnett I. The double burden of malnutrition in SE Asia and the Pacific: priorities, policies and politics. Health Policy Plan. 2015; 30(9):1193-206.

5. Ruel MT. Operationalizing dietary diversity: a review of measurement issues and research priorities. J Nutr. 2003;133(11 Suppl 2):3911S-26S.

6. Gina Kennedy GN. Basic guidelines for validation of a simple dietary diversity score as an indicator of dietary nutrient adequacy for nonbreastfeeding children 2-6 Years. 2006. ftp://ftp.fao.org/ag/agn/nutrition/ dds_validation.pdf. Accessed 15 Apr 2006.

7. Kennedy GL, Pedro MR, Seghieri C, Nantel G, Brouwer I. Dietary diversity score is a useful indicator of micronutrient intake in non-breast-feeding Filipino children. J Nutr. 2007;137(2):472-7.

8. Hatloy A, Torheim LE, Oshaug A. Food variety-a good indicator of nutritional adequacy of the diet? A case study from an urban area in Mali, West Africa. Eur J Clin Nutr. 1998;52(12):891-8.

9. Ruel M, Graham J, Murphy S, Allen L. Validating simple indicators of dietary diversity and animal source food intake that accurately reflect nutrient adequacy in developing countries. Report submitted to GLCRSP; 2004.

10. Yang XGY, Zhai FY. Report of China Nutrition and Health Survey in 2002-the third part. Beijing: People's Medical Publishing House; 2005.

11. Jiayin C. Research on the nutritional problems and its influencing factors of the children under five in China. Peking Union Medical College: Beijing; 2013.

12. Ji CY. Prevalence of anemia and its proportions for Chinese primary and secondary school students. Chin J Sch Health. 2008;2(29):111-3.

13. Black RE, Allen LH, Bhutta ZA, Caulfield LE, de Onis M, Ezzati M, et al. Maternal and child undernutrition: global and regional exposures and health consequences. Lancet. 2008;371(9608):243-60.

14. Global Report. Investing in the future- a united call to action on vitamin and mineral deficiencies. 2009. http://www.unitedcalltoaction.org. Accessed 12 Dec 2013.

15. Mallard SR, Houghton LA, Filteau S, Chisenga M, Siame J, Kasonka L, et al. Micronutrient adequacy and dietary diversity exert positive and distinct effects on linear growth in urban Zambian infants. J Nutr. 2016;146(10):2093-101.

16. Salehi-Abargouei A, Akbari F, Bellissimo N, Azadbakht L. Dietary diversity score and obesity: a systematic review and meta-analysis of observational studies. Eur J Clin Nutr. 2016;70(1):1-9.

17. Fernandez C, Kasper NM, Miller AL, Lumeng JC, Peterson KE. Association of dietary variety and diversity with body mass index in US preschool children. Pediatrics. 2016;137(3):e20152307.

18. Morris MA, Hulme C, Clarke GP, Edwards KL, Cade JE. What is the cost of a healthy diet? Using diet data from the UK Women's Cohort Study. J Epidemiol Community Health. 2014;68(11):1043-9.

19. Xue Y, Lee E, Ning K, Zheng Y, Ma D, Gao H, et al. Prevalence of picky eating behaviour in Chinese school-age children and associations with anthropometric parameters and intelligence quotient. A cross-sectional study. Appetite. 2015;91:248-55.

20. Xue Y, Zhao A, Cai L, Yang B, Szeto IM, Ma D, Zhang Y, Wang P. Growth and development in Chinese pre-schoolers with picky eating behaviour: a crosssectional study. PLoS One. 2015;10(4):e123664.

21. Yang YX. China Food Composition. Beijing: Pecking University Medical Press; 2005.

22. Yang YX, Wang GY, Pan XC. China food composition, 2nd. Beijing: Pecking University Medical Press; 2009.

23. Office for Resources, Policy Division Science and Technology Policy Bureau. Standard Tables of Food Composition in Japan. Tokyo: Ishiyaku Publishers, Inc; 2010.

24. Daniels MC, Adair LS, Popkin BM, Truong YK. Dietary diversity scores can be improved through the use of portion requirements: an analysis in young Filipino children. Eur J Clin Nutr. 2009;63(2):199-208.

25. Li H, Zong XN, Ji CY, Mi J. Body mass index cut-offs for overweight and obesity in Chinese children and adolescents aged $2-18$ years. Zhonghua Liu Xing Bing Xue Za Zhi. 2010;31(6):616-20.

26. Steyn NP, Nel JH, Nantel G, Kennedy G, Labadarios D. Food variety and dietary diversity scores in children: are they good indicators of dietary adequacy? Public Health Nutr. 2006;9(5):644-50. 
27. Zhai FY, Cao RX, Fu JJ, Wang ZH, Zhang LW. Current status of nutritional lunch in primary and high schools of Beijing. Capital J Public Health. 2007;1(1):7-12

28. Fu JJ, Zhai FY. Current situation and development tendency of nutritional lunch. Foreign Med Sci (Section Hygiene). 2005;32(2):91-5.

29. Norhaizan MJ, Nor FAA. Determination of phytate, iron, zinc, calcium contents and their molar ratios in commonly consumed raw and prepared food in malaysia. Malays J Nutr. 2009;15(2):213-22.

30. Sotelo A, Gonzalez-Osnaya L, Sanchez-Chinchillas A, Trejo A. Role of oxate, phytate, tannins and cooking on iron bioavailability from foods commonly consumed in Mexico. Int J Food Sci Nutr. 2010;61 (1):29-39.

31. Prieto RM, Fiol M, Perello J, Estruch R, Ros E, Sanchis P, et al. Effects of Mediterranean diets with low and high proportions of phytate-rich foods on the urinary phytate excretion. Eur J Nutr. 2010;49(6):321-6.

32. Isabelle Lestienne CICM. Effects of soaking whole cereal and legume seeds on iron, zinc and phytate contents. Food Chem. 2005;89:421-5.

33. Jayawardena R, Byrne NM, Soares MJ, Katulanda P, Yadav B, Hills AP. High dietary diversity is associated with obesity in Sri Lankan adults: an evaluation of three dietary scores. BMC Public Health. 2013;13:314.

34. Pinket AS, De Craemer M, Huybrechts I, De Bourdeaudhuij I, Deforche B, Cardon G, et al. Diet quality in European pre-schoolers: evaluation based on diet quality indices and association with gender, socio-economic status and overweight, the ToyBox-study. Public Health Nutr. 2016;19(13):2441-50.

\section{Submit your next manuscript to BioMed Central and we will help you at every step:}

- We accept pre-submission inquiries

- Our selector tool helps you to find the most relevant journal

- We provide round the clock customer support

- Convenient online submission

- Thorough peer review

- Inclusion in PubMed and all major indexing services

- Maximum visibility for your research

Submit your manuscript at www.biomedcentral.com/submit 